\title{
Effect of counseling based on PLISSIT model on sexual function of HIV-positive married women
}

\author{
Leila Asadi ${ }^{1}$, Tayebe Ziaei ${ }^{1}$, Hamid Emadi Koochak ${ }^{2,3}$, Ali Montazeri', Elham Rezaei ${ }^{5}$, \\ Zahra Behboodi Moghadam ${ }^{5}$, Leila Shahmohammadi ${ }^{6}$
}

${ }^{1}$ Counseling and Reproductive Health Research Centre, Golestan University of Medical Sciences, Gorgan, Iran

${ }^{2}$ Department of Infectious Diseases, Tehran University of Medical Sciences, Tehran, Iran

${ }^{3}$ Iranian Research Center for HIV/AIDS, Iranian Institute for Reduction of High Risk Behaviors, Tehran University of Medical

Sciences, Tehran, Iran

${ }^{4}$ Mental Health Research Group, Health Metrics Research Centre, Iranian Institute for Health Sciences Research, ACECR,

Tehran, Iran

${ }^{5}$ School of Nursing and Midwifery, Tehran University of Medical Sciences, Tehran, Iran

${ }^{6}$ Behavioral Disease Counselling Center of Imam Khomeini Hospital, Tehran University of Medical Sciences, Tehran, Iran

\begin{abstract}
Introduction: In recent years, Iran has witnessed a considerable increase in the number of women with human immunodeficiency virus (HIV). People living with HIV are the main subject in sexual health behavior, but the focus is more on the risks that are associated with their sexual behavior, and aspects such as their sexual satisfaction, which is one the most important components of quality of life, is often ignored. Disregarding these important aspects may lead to an increase to the prevalence of the disease. This study aimed to investigate the effect of counseling based on PLISSIT model on sexual function of HIV-positive married women.

Material and methods: This clinical trial study was conducted on $60 \mathrm{HIV}$-positive married women (30 in the intervention group and 30 in the control group) with impaired sexual function. Female Sexual Function Index (FSFI) was used to measure a sexual function of these women. All participants in both groups, if did not have a depression (the score less than 14 in Beck Depression Inventory [BDI] questionnaire and score less than 28 in FSFI questionnaire), were considered as women with sexual disorder. The samples were randomly divided into two intervention and the control groups. Sampling was done using table of random numbers. Counseling sessions in the intervention group was based on the steps of PLISSIT models, and the sessions were conducted by the researchers with an interval of one week for 3 hours in average. Sexual function in three stages (before intervention, one month, and three months after the intervention) was measured. The software SPSS version 20 was used for data analysis.

Results: According to the results, score of sexual function before the intervention in both groups did not differ significantly $(p>0.05)$. At the end of the first month, the sexual function score increased in the intervention group and reduced in the control group, and differences between the two groups compared to baseline in each group were statistically significant $(p<0.05)$. The increase in the sexual function score in the intervention group and decrease of the sexual function score in the control group led to a statistically significant difference in the measurement at the third month $(p<0.05)$. Changes in sexual function scores between the first and third months in the intervention group were statistically significant $(p<0.05)$.
\end{abstract}

Address for correspondence: Dr. Zahra Behboodi Moghadam, School of Nursing and Midwifery, Tehran University of Medical Sciences, Tehran, Iran, phone: 00989122494201,

e-mail: behboodi@tums.ac.ir
Article history:

Received: 01.11.2017

Received in revised form: 30.12 .2017

Accepted: 02.01.2018

Available online: 15.08.2018
International Journal of HIV-Related Problems

HIV \& AIDS

R e v i e w 
Conclusions: According to the findings of this study, counseling based on PLISSIT model positively affected the sexual function of HIV-positive women. Therefore, this model as a cost-effective and simple counseling method can be used to improve health and quality of life of these women.

HIV AIDS Rev 2018; 17, 3: 169-175

DOI: https://doi.org/10.5114/hivar.2018.78487

Key words: counseling, PLISSIT model, sexual function, HIV/AIDS.

\section{Introduction}

Acquired immunodeficiency syndrome (AIDS) is a global pandemic and cases of AIDS have been reported in almost every country [1]. This disease, due to the its rapid spread, has had a unique prevalence and severity in human history, and has been called the plagues of the century [2].

According to World Health Organization (WHO) and Joint United Nations Programme on HIV and AIDS (UNAIDS) statistics, at the end of 2015, 36.7 million people worldwide were living with human immunodeficiency virus (HIV), and 2.1 million new cases have been reported in the same year. Furthermore, 1.1 million people have died of AIDS-related causes in 2015 [3]. The latest statistics of the population with the virus in Iran show that, up to 21 September 2014, about 28,663 people were living with HIV, which indicates that the number of women with the virus and transmission of virus through sexual relations have increased compared to previous years [4].

HIV infection, due to its own nature, affects all aspects of patients' lives and even seriously influence the health of society [5]. Most affected people have experienced instability in their lives [6].

HIV-positive people are the main subject in sexual health behavior, but the focus is more on the risks that are associated with their sexual behavior and other aspects of life such as their sexual satisfaction, which is one of the most important components of quality of life that is often ignored. Disregarding these aspects may lead to an increase in the prevalence of the disease [7]. Because physical and psychological pressures arising from inadequate satisfaction of sexual desire, leads to the feeling of deprivation, insecurity, and unhappiness as well as social problems such as crime, sexual abuse, and mental illness [8-10].

AIDS patients feel guilty because their behaviors, particularly sexual behavior, endanger others. Feeling of developing a transmissible agent in the body can cause patients to think that they are driven away and rejected by others [11]. Ignoring sexual instinct for a long time creates irreparable problems in human, and often leads to sexual disorder, sexual dissatisfaction in couples, and family breakdown [12].

Sexual function plays a very important role in today's world, and sexual dysfunction has an undeniable role on quality of life and self-confidence of the married couples. The inability to establish a safe and enjoyable relationship with a partner has many physical, psychological, and social consequences for the woman and her husband [13]. Sexual function is a cycle of sexual response and its process, including desire, arousal, virginal lubrication, orgasm, and subsidence [14].

Since sexual function is a taboo for many people in society and people often don not talk about it, it therefore gets ignored by healthcare personnel who do not pay enough attention to this factor during patients' assessment [15]. Whereas, a good sexual relation that satisfies both partners play a crucial role in the success and sustainability of family structure [16]. Sexual dysfunction is common in women and causes serious problems in family life and quality of life $[17,18]$. The levels of anxiety and depression in HIV-positive women were more than HIV-positive men [19]. More than half of sexual problems that destroy marital life are caused by insufficient knowledge or wrong beliefs about sexual relation [20].

Counseling could give couples information that is required to create a sexual life, so they could use this information to develop and evolve their marital life [21]. When sexual relation gets better and more satisfactory for couples, all relations between them also get better in an efficient way [22].

There are various frameworks for sexual counseling that can help healthcare providers to implement an appropriate and effective strategy to support and intervene, if couples have sexual concerns or problems [23].

PLISSIT model, which was first introduced by Annon in 1974 , is the most widely used model in sexual assessment and counseling [24]. The PLISSIT model, which has been created by using the first letters of words: permission (P), limited information (LI), specific suggestion (SS), and intensive therapy (IT), was developed from very beginning to examine and respond to the existing needs regarding promotion of sexual function in people with disability or chronic diseases [25]. This patient-centered model can be used as a suitable guide by healthcare workers to examine the sexual concerns of patients with chronic diseases and identify their sexual problems [26].

Stigmatization is considered as the most important factor that limits and prevents HIV/AIDS patients from receiving health care and services [27]. People with HIV/AIDS create a specific group in civil right studies, who due to stigmatization and labelling by society that views them as unethical and pervert people, are being deprived from their rightful place in the community. Stigmatization and discrimination associated with HIV/AIDS is a global concern [28]. 
Healthcare professional who provide care for these patients, due to wrong beliefs and fear of getting infected, show behaviors that intensify the feeling of guilt and discrimination in patients, and this leads to self-limiting reaction in them and prevents them from seeking healthcare services [29].

There are numerous studies about the stigmatization and discrimination experienced by patients with HIV/AIDS from society and even healthcare workers, showing that these people are rejected by the society [30,31].

Although these patients receive healthcare services, with health centers mainly providing education on preventing high-risk behaviors, mental-psychological counseling, laboratory tests and drug treatment; the counseling is mostly focused on risks that are associated with their sexual behaviors. This issue shows the importance of counseling and educational interventions for these patients.

Researchers in their investigation did not find any study on the effect of counseling on improving sexual function in women with HIV/AIDS. Therefore, this study aimed to investigate the effect of counseling based on PLISSIT model on sexual function of married HIV-positive women. It is hoped that this study can be an effective step towards improving public health, especially women's health, which has a significant effect on the health indexes.

\section{Material and methods}

This randomized clinical trial with two intervention and control groups was conducted in 2016 on $60 \mathrm{HIV}$-positive married women (30 in intervention and 30 in control groups). Study setting was the behavioral health center of Imam Khomeini (RA) in Tehran. Inclusion criteria included: being in a stable relationship with a spouse, having a HIV-neg- ative partner, being diagnosed with HIV virus for at least 3 months, being able to at least read and write, having no history of participation in training classes or consulting session with a focus on sexual function, not using alcohol and drugs, lack of chronic diseases, lack of depression, not using drugs that affect sexual function, and not being pregnant. Exclusion criteria included: death of the spouse, divorce, or severe marital conflict during the study, unwilling to continue participation in the study, pregnancy during the study, and diagnosis of mental-psychological illness during the study.

This study was approved by the ethics committee of the Tehran University of Medical Sciences dated 20 January 2016, with the number IR.TUMS.REC.1394.1705. It was also recorded in the database of the Ministry of Health with the number of IRCT201211179463N10.

Data collecting tools included demographic, Female Sexual Function Index (FSFI), and Beck Depression Inventory (BDI) questionnaires. Demographic questionnaire had 3 parts: personal information, midwifery, and information related to the disease. Validity of the questionnaire was obtained through content validity method. The Persian FSFI questionnaire contained 19 questions with 5 options that evaluated sexual desire, arousal, vaginal lubrication, orgasm, sexual satisfaction, and sexual pain. Questions 1-2 evaluated sexual desire; questions 3-6 evaluated stimulation (arousal); questions 7-10 assessed the virginal lubrication; questions 11-13 evaluated orgasms; questions 14-16 were about sexual satisfaction, and questions 17-19 were about the sexual pain during sex. According to the questionnaire's developer, score of each domain is calculated by summing up the scores of each area, multiplied with coefficient of each section. For instance, sexual desire coefficient was (0.6), sexual arousal (0.3), vaginal lubrication (0.3), orgasm (0.4), sexual satisfac-

Approval of Ethical Committee of Tehran University of Medical Sciences with the number: IR.TUMS.REC.1394.1705 Registered in clinical trials database of Ministry of Health with the number: IRCT201211179463N10

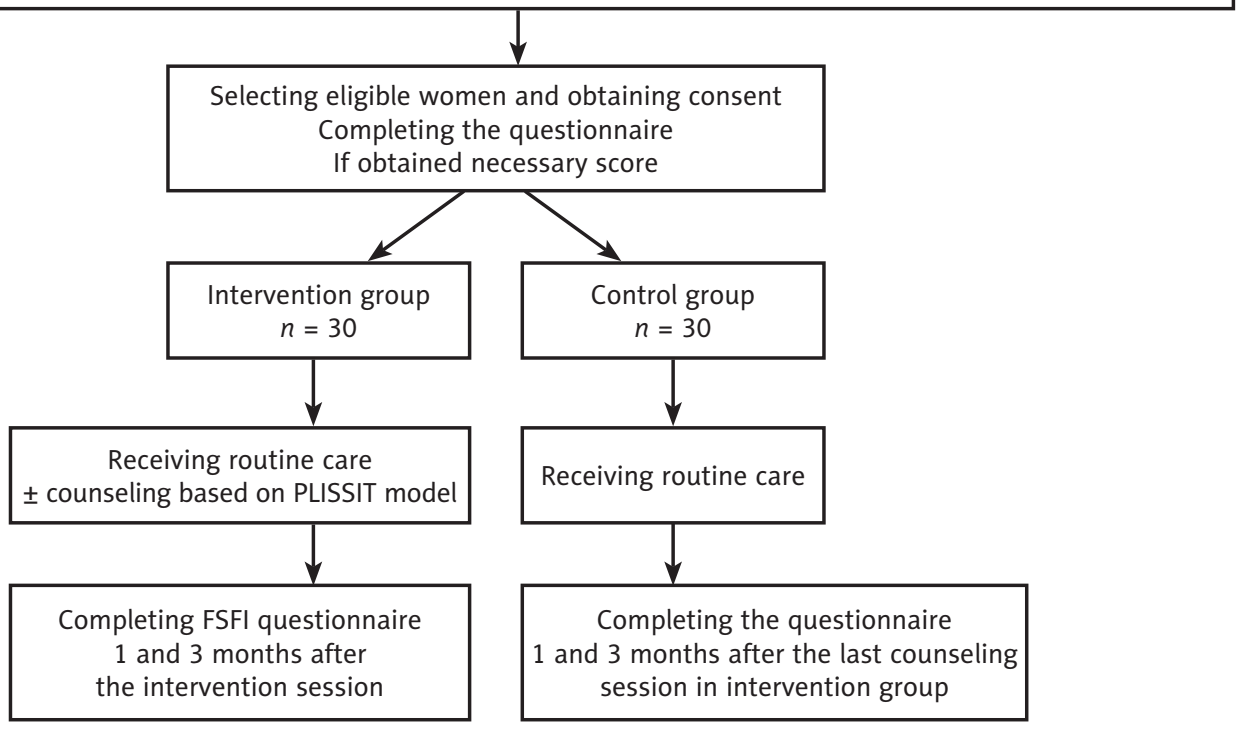

Fig. 1. Inclusion flowchart 
Table 1. Demographic characteristics in both intervention and control groups

\begin{tabular}{|c|c|c|c|}
\hline Groups & $\begin{array}{c}\text { Control } \\
n=30(\%)\end{array}$ & $\begin{array}{c}\text { Intervention } \\
n=30 \text { (\%) }\end{array}$ & $p$ value \\
\hline \multicolumn{3}{|l|}{ Age (year) } & \multirow{4}{*}{$0.41^{*}$} \\
\hline $20-30$ & 11 & 14 & \\
\hline $30-40$ & 16 & 14 & \\
\hline$\geq 40$ & 3 & 2 & \\
\hline \multicolumn{3}{|l|}{ Educational level } & \multirow{5}{*}{$0.30^{* *}$} \\
\hline Primary school & 3 & 2 & \\
\hline Secondary school & 4 & 10 & \\
\hline High school & 18 & 13 & \\
\hline Academic & 5 & 5 & \\
\hline \multicolumn{3}{|l|}{ Occupation } & \multirow{3}{*}{$0.09^{\star * *}$} \\
\hline Homey & 8 & 3 & \\
\hline Employee & 22 & 27 & \\
\hline \multicolumn{3}{|c|}{ Socioeconomically status } & \multirow{4}{*}{$0.17^{\star *}$} \\
\hline Good & 7 & 9 & \\
\hline Moderate & 18 & 11 & \\
\hline Bad & 5 & 10 & \\
\hline \multicolumn{3}{|l|}{ Number of children } & \multirow{4}{*}{$0.10^{\star *}$} \\
\hline 0 & 6 & 8 & \\
\hline 1 & 19 & 16 & \\
\hline$\geq 2$ & 5 & 6 & \\
\hline \multicolumn{3}{|l|}{ Husband's age (year) } & \multirow{4}{*}{$0.36^{*}$} \\
\hline $20-30$ & 2 & 5 & \\
\hline $30-40$ & 17 & 14 & \\
\hline$\geq 40$ & 11 & 11 & \\
\hline \multicolumn{3}{|c|}{ Husband's educational level } & \multirow{5}{*}{$0.51^{\star *}$} \\
\hline Primary school & 2 & 4 & \\
\hline Secondary school & 10 & 8 & \\
\hline High school & 16 & 13 & \\
\hline Academic & 2 & 5 & \\
\hline \multicolumn{3}{|l|}{ Husband's occupation } & \multirow{3}{*}{$0.08^{\star * *}$} \\
\hline Unemployed & 9 & 5 & \\
\hline Employee & 21 & 25 & \\
\hline \multicolumn{3}{|c|}{ Duration of marriage (year) } & \multirow{4}{*}{$0.63^{\star *}$} \\
\hline$<5$ & 11 & 12 & \\
\hline $5-10$ & 10 & 14 & \\
\hline$\geq 10$ & 9 & 4 & \\
\hline \multicolumn{3}{|c|}{ Duration of disease (year) } & \multirow{4}{*}{$0.66^{\star \star \star \star}$} \\
\hline$<1$ & 1 & 1 & \\
\hline $1-5$ & 19 & 16 & \\
\hline$\geq 5$ & 10 & 12 & \\
\hline \multicolumn{3}{|l|}{ Menstrual status } & \multirow{3}{*}{$0.54^{\star \star *}$} \\
\hline Regular & 24 & 22 & \\
\hline Irregular & 6 & 8 & \\
\hline
\end{tabular}

tion (0.4), and sexual pain was (0.4). The score of 28 or higher indicated no sexual dysfunction, and scores below 28 indicated the existence of sexual dysfunction. Reliability and validity of the Persian version of this questionnaire have been confirmed by several researchers in previous years, and the value of reliability scales, which was determined by calculating Cronbach's a coefficient $\geq 0.7$ has been approved by [32, 33]. BDI (Persian version), which includes 21 questions has been developed to assess feedback and symptoms of depression, and its score ranges from a minimum of 0 to a maximum of 63. By summing up the individual's scores on each item, the individual's score is obtained directly. The scores of 0-13 indicate no or minimal depression, 14-19 indicate minor depression, 20-28 moderate depression, and the scores of 29-63 indicate severe depression. The reliability and validity of this questionnaire for use in a clinical setting has been confirmed by Cronbach's $\alpha$ coefficient of 0.7 to 0.9 [34].

The researcher, after obtaining necessary permissions, attended behavioral health center of Imam Khomeini in Tehran, and selected the study participants from HIV-positive women attending the center. Then, based on inclusion criteria, qualified individuals were invited to participate in the study after being explained about the aims and method of the study, and giving informed consent. The eligible women after completing the questionnaires and obtaining necessary scores that indicated they had no depression $(\mathrm{BDI}<14)$ and had sexual dysfunction (FSFI $>28$ ), were divided into the intervention and control groups (30 in intervention and 30 in control groups) using table of random numbers (Figure 1). In the intervention group, individual counseling based on PLISSIT model was conducted in a quiet and private place by a research team member. The number of counseling session for each individual was determined by the researcher based of the individual's need, desire, and progress during the course of the counseling, which was usually once a week for 3 hours.

The first consultation session and in the limited information step, presented information about the reasons of sexual dysfunction, physiology, and anatomy of the female sexual organs in women with HIV. During the first, second, and third counseling session, the priorities and needs of each individual to improve her sexual function, with regards to the issues raised by her and the researcher's examination were investigated. Specific suggestions were designed according to each person's sexual problems. If any signs of mental-psychological disorder or interpersonal relationship associated with sexual function were observed and identified during the counseling sessions, which required specific (IT) treatment, the individual was referred to the appropriate departments.

One and three months after the last session of counseling for each participant, FSFI questionnaires were completed again by participants. In the control group, one and three months after completing the initial questionnaire, the FSFI questionnaire was also completed again. However, routine care was similar for both groups during the study. At the end, to appreciate the participation in the control group, an educational booklet on sex- 
Table 2. Comparison female sexual function and sexual subscale in both intervention and control groups

\begin{tabular}{|c|c|c|c|c|c|c|c|}
\hline \multirow{2}{*}{$\begin{array}{l}\text { Sexual } \\
\text { function }\end{array}$} & \multirow{2}{*}{ Groups } & $\begin{array}{c}\text { Before } \\
\text { intervention }\end{array}$ & $\begin{array}{l}\text { After } 1 \text { month } \\
\text { of intervention }\end{array}$ & $\begin{array}{l}\text { After } 3 \text { months } \\
\text { of intervention }\end{array}$ & \multirow{2}{*}{$\begin{array}{c}p \text { value } \\
\text { (between } \\
\text { before and } \\
1 \text { month) }\end{array}$} & \multirow{2}{*}{$\begin{array}{l}p \text { value } \\
\text { (between } \\
\text { one and } \\
3 \text { month) }\end{array}$} & \multirow{2}{*}{$\begin{array}{l}p \text { value } \\
\text { with in }\end{array}$} \\
\hline & & Mean \pm SD & Mean \pm SD & Mean \pm SD & & & \\
\hline \multirow{3}{*}{$\begin{array}{l}\text { Sexual } \\
\text { desire }\end{array}$} & \multirow{3}{*}{$\begin{array}{l}\text { Intervention } \\
\text { Control }\end{array}$} & $3.40 \pm 0.92$ & $3.72 \pm 0.82$ & $3.93 \pm 0.80$ & \multirow{3}{*}{$\begin{array}{c}0.01^{\star *} \\
0.001^{\star *}\end{array}$} & \multirow{3}{*}{$\begin{array}{l}0.11^{\star \star} \\
0.16^{\star \star}\end{array}$} & \multirow{3}{*}{$\begin{array}{l}<0.001^{* * *} \\
<0.001^{* * *}\end{array}$} \\
\hline & & $3.38 \pm 0.82$ & $3.00 \pm 0.61$ & $2.90 \pm 0.63$ & & & \\
\hline & & ${ }^{*} p=0.70$ & ${ }^{\star} p=0.001$ & ${ }^{*} p<0.001$ & & & \\
\hline \multirow{3}{*}{$\begin{array}{l}\text { Sexual } \\
\text { exciting }\end{array}$} & \multirow{3}{*}{$\begin{array}{l}\text { Intervention } \\
\text { Control }\end{array}$} & $3.38 \pm 0.74$ & $4.14 \pm 0.76$ & $4.34 \pm 0.63$ & \multirow{3}{*}{$\begin{array}{c}<0.001^{\star *} \\
0.09^{\star *}\end{array}$} & \multirow{3}{*}{$\begin{array}{l}0.03^{\star \star} \\
0.92^{\star \star}\end{array}$} & \multirow{3}{*}{$\begin{array}{c}<0.001^{* * *} \\
0.61^{* * *}\end{array}$} \\
\hline & & $3.19 \pm 1.01$ & $3.43 \pm 0.84$ & $3.36 \pm 0.89$ & & & \\
\hline & & ${ }^{*} p=0.33$ & ${ }^{*} p<0.001$ & ${ }^{*} p<0.001$ & & & \\
\hline \multirow{3}{*}{$\begin{array}{l}\text { Vaginal } \\
\text { moisture }\end{array}$} & \multirow{3}{*}{$\begin{array}{c}\text { Intervention } \\
\text { Control }\end{array}$} & $3.94 \pm 0.72$ & $4.67 \pm 0.77$ & $5.02 \pm 0.76$ & \multirow{3}{*}{$\begin{array}{c}0.001^{\star *} \\
0.18^{\star \star}\end{array}$} & \multirow{3}{*}{$\begin{array}{l}0.01^{\star *} \\
0.47^{\star *}\end{array}$} & \multirow{3}{*}{$\begin{array}{c}<0.001^{* * *} \\
0.10^{\star * *}\end{array}$} \\
\hline & & $4.13 \pm 0.98$ & $3.95 \pm 1.09$ & $3.86 \pm 0.80$ & & & \\
\hline & & ${ }^{*} p=0.45$ & ${ }^{*} p=0.006$ & ${ }^{*} p<0.001$ & & & \\
\hline \multirow{3}{*}{ Orgasms } & \multirow{3}{*}{$\begin{array}{l}\text { Intervention } \\
\text { Control }\end{array}$} & $4.16 \pm 1.01$ & $4.90 \pm 0.75$ & $5.19 \pm 0.58$ & \multirow{3}{*}{$\begin{array}{c}<0.001^{\star *} \\
0.20^{\star *}\end{array}$} & \multirow{3}{*}{$\begin{array}{c}0.009^{\star *} \\
0.33^{\star *}\end{array}$} & \multirow{3}{*}{$\begin{array}{c}<0.001^{* * *} \\
0.06^{* * *}\end{array}$} \\
\hline & & $4.13 \pm 1.02$ & $3.99 \pm 1.04$ & $3.87 \pm 0.92$ & & & \\
\hline & & ${ }^{*} p=0.89$ & ${ }^{*} p=0.001$ & ${ }^{*} p<0.001$ & & & \\
\hline \multirow{3}{*}{$\begin{array}{c}\text { Sexual } \\
\text { satisfaction }\end{array}$} & \multirow{3}{*}{$\begin{array}{l}\text { Intervention } \\
\text { Control }\end{array}$} & $4.73 \pm 0.99$ & $5.18 \pm 0.71$ & $5.32 \pm 0.72$ & \multirow{3}{*}{$\begin{array}{l}0.001^{\star *} \\
0.002^{* *}\end{array}$} & \multirow{3}{*}{$\begin{array}{l}0.10^{* *} \\
0.37^{* *}\end{array}$} & \multirow{3}{*}{$\begin{array}{l}<0.001^{* * *} \\
<0.001^{* * *}\end{array}$} \\
\hline & & $4.51 \pm 1.00$ & $4.08 \pm 0.86$ & $3.96 \pm 1.05$ & & & \\
\hline & & ${ }^{*} p=0.35$ & ${ }^{*} p<0.001$ & ${ }^{*} p<0.001$ & & & \\
\hline \multirow{3}{*}{ Sexual pain } & \multirow{3}{*}{$\begin{array}{c}\text { Intervention } \\
\text { Control }\end{array}$} & $4.28 \pm 1.49$ & $4.60 \pm 1.10$ & $5.05 \pm 0.90$ & \multirow{3}{*}{$\begin{array}{l}0.21^{* *} \\
0.62^{* *}\end{array}$} & \multirow{3}{*}{$\begin{array}{c}0.001^{\star *} \\
0.08^{\star *}\end{array}$} & $0.001^{* * *}$ \\
\hline & & $4.24 \pm 1.53$ & $4.26 \pm 1.29$ & $4.06 \pm 1.22$ & & & $0.20^{\star * *}$ \\
\hline & & ${ }^{*} p=0.92$ & ${ }^{*} p=0.28$ & ${ }^{*} p=0.001$ & & & \\
\hline Total score & Intervention & $23.89 \pm 3.62$ & $27.08 \pm 2.91$ & $28.91 \pm 2.00$ & $<0.001^{* *}$ & $<0.001^{\star *}$ & $<0.001^{* * *}$ \\
\hline of sexual & Control & $23.64 \pm 3.37$ & $22.73 \pm 3.59$ & $21.97 \pm 3.41$ & $0.03^{\star *}$ & $0.008^{\star \star}$ & $0.001^{\star \star *}$ \\
\hline function & & ${ }^{*} p=0.76$ & ${ }^{*} p<0.001$ & ${ }^{*} p<0.001$ & & & \\
\hline
\end{tabular}

*Mann-Whitney $U$ test, ${ }^{* \star W i l c o x o n ~ t e s t, ~}{ }^{* * *}$ Freedman test

ual response and cycle of sexual response in woman were given after completion of the last questionnaire. The phone number of first author was given to the partakers and offered participating in the counseling session based on PLISSIT model after data collection. Finally, the findings were analyzed based on the normality or non-normality of parametric or non-parametric tests, using SPSS software version 20.

\section{Results}

In this study, participants in both intervention and control groups first completed the three demographic, BDI, and FSFI questionnaires, and then, 1 and 3 months after the intervention, the FSFI questionnaire was assessed once again. As shown in Table 1, the two groups were homogenous in terms of demographic characteristics $(p>0.05)$.

The average age of participants in the intervention group was $31.46 \pm 5.81$ years, and in the control group was 30.23 \pm 5.93 years. The mean duration of disease in the intervention group was $4.77 \pm 4.03$ and $4.86 \pm 3.63$ in the control group, and two groups were similar in terms of other demographic and obstetric characteristics $(p>0.05)$.

In this study, the FSFI showed no significant difference in the two groups before the intervention $(p=0.76)$. Nevertheless, the mean score of sexual functioning 1 and 3 months after the intervention showed an increase in the intervention group and a decrease in the control group. These changes in both groups were statistically significant $(p<0.0001$ in the intervention and $p=0.001$ in the control group). The changes occurred in sexual subscales in both groups are shown in Table 2.

\section{Discussion}

The results of this study showed that counseling based on PLISSIT model had a positive effect on the total scores of sexual function and subscales of sexual function in HIV-positive married women. Before the intervention, the mean score in the control and intervention groups showed no statistically significant differences $p=0.76$. However, 1 and 3 months after the intervention, the score of sexual functioning showed a significant increase in the intervention group and a decrease in the control group $(p>0.05)$ (Table 2).

Results of similar studies on the effects of counseling based on PLISSIT model on women's sexual function confirm our findings. Rostamkhani et al. conducted a study based on FSFI in 80 married women (20 in intervention and 20 in the control group) with at least one sexual problem, and showed a significant increase in the mean score of sexual function of women in 2 weeks $(p<0.001)$ and 4 weeks $(p<0.001)$ after the intervention (28.8 and 28.4, respective- 
ly) compared with the baseline sexual functioning score (25.3) before the intervention [35].

Furthermore, Tutuncu et al. in their study of 70 women who had hysterectomy ( 35 in the intervention and 35 in control group), which was conducted in midwifery department of Istanbul Hospital showed that educating women based on PLISSIT model had a positive effect on their sexual functioning and problem solving skills related to sexual relation 3 months $(p=0.00)$ and 6 months $(p=0.00)$ after the surgery [36]. Farnam et al. in a study entitled "Effect of PLISSI and SHM on sexual problems of women in Tehran" used BISF-W to evaluate their sexual function, and concluded that counseling based on these models had a positive effect on sexual function of these women. Analysis between the two groups showed that problems affecting sexual function in the PLISSIT group were significantly reduced and "sexual distress" in the SHM group was less $(p<0.05)$ [37].

In the study of Torkzahrani et al., which was conducted on 90 women (45 in the intervention and 45 control groups), who were breastfeeding their first child and had at least one sexual problem (based on questionnaires FSFI), a positive effect of counseling based on PLISSIT model was seen in the intervention group 4 weeks after the counseling intervention $(p<0.001)$ [38]. Furthermore, the study of Behboodi et al. entitled "The impact of sexual health education program on sexual function of women in Iran", which was conducted on 90 married women in two intervention $(n=45)$ and control groups $(n=45)$ showed that 8 weeks after the intervention (sexual education program), sexual function in all aspects including: sexual desire $(p=0.006)$, excitement $(p=0.006)$, vaginal lubrication $(p=0.002)$, sexual satisfaction $(p=0.011)$, and overall score ( $p=0.001)$ had improved [39].

Numerous studies have been conducted on counseling based on PLISSIT model on sexual function of women with different chronic diseases in public population, but in women with HIV-positive, due to negative assumption about this disease and stigmatization of the society, studies of different aspects of sexual functioning and the need for counseling and education in this group of women are somehow unique. The results of this study showed that, sexual counseling based on PLISSIT model can positively improve the sexual function in HIV-positive women.

\section{Conclusions}

According to the findings of this study, counseling based on PLISSIT model positively affected the sexual function of HIV-positive women. Therefore, this model as a cost-effective and simple counseling method can be used to improve the health and quality of life of these women.

\section{Acknowledgments}

The authors would like to express their gratitude to the participants. Without them, writing of this paper would be impossible.

\section{Conflict of interest}

The authors declare no potential conflicts of interest with respect to the research, authorship, and/or publication of this article.

\section{References}

1. Longo DL, Fauci A, Kasper DL, et al. Harrison's Principles of Internal Medicine. McGraw-Hill, New York 2012.

2. Najarkolaei F, Niknami SH, Shokravi F, Ahmadi F. Perception and behaviors of HIV/AIDS patients: A qualitative study. J Kermanshah Univ Med Sci 2009; 13: 220-234.

3. World Health Organization. HIV/AIDS. 2016. Available at: http:// www.who.int.

4. Islamic Republic of Iran AIDS Progress Report. On Monitoring of the United Nations General Assembly Special Session on HIV and AIDS. March 2015. Available at: http://www.unaids.org.

5. Mohammadpour A, Parsa Yekta Z, Nikbakht Nasrabadi A. Spirituality in HIV-infected Individuals: A Phenomenological Study. Journal of Hayat 2011; 17: 52-63.

6. Behboodi-Moghadam Z, Nikbakht-Nasrabadi A, Ebadi A, et al. Fertility Desire in Iranian Women with HIV: A Qualitative Study. Iran J Public Health 2015; 44: 1126-1134.

7. Selley J, Russell S, Khana K, et al. Sexual partnerships established by HIV-infected persons taking anti-retroviral therapy in Eastern Uganda. Culture Health Sex 2009; 11: 703-716.

8. Zeighami Mohammadi S, Ghaffari F. Sexual dysfunction among hypertensive women referred to health centers of Ramsar and Tonekabon (2009). Modern Care Journal 2012; 8: 212-220.

9. Mooshkbid-Haghighi M, Shams-Mofarahe Z, Majd-Timory MM, Hosseini F. The effect of marital counseling on sexual satisfaction of couples, Shiraz, 1380. Iran J Nursing 2002; 15: 15-19.

10. Mangassarian S, Sumner L, O'Callaghan E. Sexual impulsivity in women diagnosed with borderline personality disorder: a review of the literature. Sexual Addiction \& Compulsivity 2015; 22: 195-206.

11. Folayan MO, Harrison A, Brown B, et al. Associations between Forced Sexual Initiation, HIV Status, Sexual Risk Behavior, Life Stressors, and Coping Strategies among Adolescents in Nigeria. PLoS One 2016; 11: 220-212.

12. Pakgohar M, Vizheh M, Babaee G, et al. Effect of counseling on sexual satisfaction among infertile women referred to Tehran fertility center. Journal of Hayat 2008; 14: 21-30.

13. Bahrami N, Alizadeh S, Bahrami S. Sexual dysfunctions and associated factors in women of reproductive age. Journal of Shahid Beheshti School of Nursing \& Midwifery 2012; 21: 9-15.

14. Jonathan S, et al. Berek \& Novak's Gynecology. $15^{\text {th }}$ ed. Lippincott Williams and Wilkins, Philadelphia 2012.

15. Avci D, Dogan S. The Impact of Sexual Dysfunction on Quality of Life of Patients with Asthma in Turkey. Sexuality and Disability 2016; 1-12.

16. Aliakbari Dehkordi M. Relationship between women sexual function and marital adjustment. J Behav Sci 2010; 4: 11-12.

17. Hoseini Tabaghdehi M, Haji Kazemi E, Hoseini F. The Relative Frequency of Sexual Dysfunction and Some related Factors in the Women Referred to the Health Centers of Sari City (2006). Journal of Mazandaran University of Medical Sciences (JMUMS) 2012; 22: 101-108.

18. Mazinani R, Akbari Mehr M, Kaskian A, Kashanian M. Evaluation of prevalence of sexual dysfunctions and its related factors in women. Razi Journal of Medical Sciences 2013; 19: 59-66.

19. Saadat M, Behboodi ZM, Saadat E. Comparison of depression, anxiety, stress, and related factors among women and men with human immunodeficiency virus infection. J Hum Reprod Sci 2015; 8: 48. 
20. Ebrahimipour H, Jalambadany Z, Peyman N, et al. Effect of sex education, based on the theory of planned behavior, on the sexual function of the woman attending Mashhad health centers. Journal of Birjand University of Medical Sciences 2013; 20: 58-67.

21. Pakgohar M, Vizheh M, Babaee G, et al. Effect of counseling on sexual satisfaction among infertile women referred to Tehran fertility center. Journal of Hayat 2008; 14: 21-30.

22. Bolurian Z, Ganjloo J. Sexual dysfunction and some related factors in women referred to health centers in Sabzevar Care centers. Journal of Reproduction and Infertility 2007; 8: 163-170.

23. Mofid V, Ahmadi A, Etemadi O. The comparison of cognitive-behavioral counseling and solotion oriented counseling on woman's sexual satisfaction in Isfahan. J Woman Soc 2014; 5: 67-83 [Article in Persian].

24. Ayaz S, Kubilay G. Effectiveness of the PLISSIT model for solving the sexual problems of patients with stoma. J Clin Nurs 2009; 18 : 89-98.

25. Sung S, Jeng C, Lin Y. Sexual health care for women with dyspareunia. Taiwanese Journal of Obstetrics \& Gynecology 2011; 50: 268-274.

26. Rutte A, van Oppen P, Nijpels G, et al. Effectiveness of a PLISSIT model intervention in patients with type 2 diabetes mellitus in primary care: design of a cluster-randomised controlled trial. BMC Family Practice 2015; 16: 69.

27. Li J, Assanangkornchai S, Lu L, et al. Development of internalized and personal stigma among patients with and without HIV infection and occupational stigma among health care providers in Southern China. Patient Preference and Adherence 2016; 10: 2309-2320.

28. Samavati Piroz A, Shirzad Nazarlo Z. People living with HIV/AIDS Figurative citizens with symbolic rights. Iran J Med Law 2008; 2 : 13-52.

29. Majumdar B, Mazaleni N. The experience of people living with HIV/ AIDS and of their direct informal caregivers in a resource-poor setting. J Int AIDS Soc 2010; 13.

30. Darrow WW, Montanea JE, Gladwin H. AIDS-related stigma among Black and Hispanic young adults. AIDS Behav 2009; 13: 1178-1188.

31. Ghouth AS. Role of Stigma and Discrimination in People Living with HIV (PLHIV) in Hadramout Governorate/Yemen. J Community Med Public Health Care 2016; 3: 100011.

32. Mohammadi KH, Heydari M, Faghihzadeh S. The Female Sexual Function Index (FSFI): validation of the Iranian version. Payesh 2008; 7: 269-278.

33. Fakhri A, Mohammadi-Zeydi E, Pakpour HA, et al. Psychometric properties of the Persian version of the Female Sexual Function Index. Sci Med J 2011; 10: 345-354.

34. Dabson KS, Mohammad Khani P. Psychometric characteristics of Beck Depression Inventory-II in patients with major depressive disorder. J Rehab 2007; 8: 82-88.

35. Rostamkhani F, Ozgoli G, Khoei EM, et al. Effectiveness of the PLISSIT-based counseling on sexual function of women. Journal of Shahid Beheshti School of Nursing \& Midwifery 2012; 22.

36. Tutuncu B, Yildiz H. The Influence on Women's Sexual Functions of Education Given According to the PLISSIT Model after Hysterectomy. Procedia-Social and Behavioral Sciences 2012; 47: 2000-2004

37. Farnam F, Janghorbani M, Raisi F, et al. Compare the effectiveness of PLISSIT and sexual health models on Women's sexual problems in Tehran, Iran: a randomized controlled trial. J Sex Med 2014; 11 : 2679-2689.

38. Torkzahrani S, Ozgoli G, Azad M, Mahmoudikohani F. The effectiveness of consultation based on PLISSIT model on sexual function of lactating women. Journal of Urmia Nursing and Midwifery Faculty 2016; 14: 639-647.

39. Behboodi Moghadam Z, Rezaei E, Khaleghi Yalegonbadi F, et al. The effect of sexual health education program on women sexual function in Iran. J Res Health Sci 2015; 15: 124-128. 